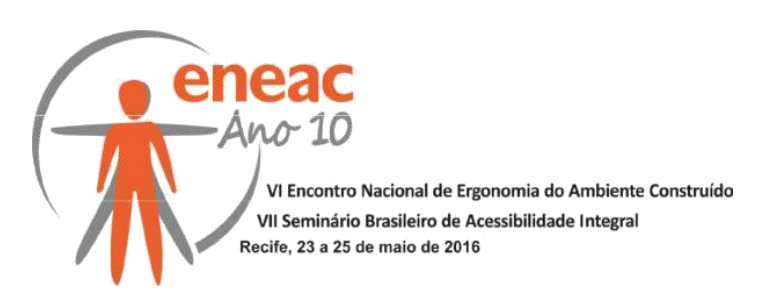

\title{
ANÁLISE DAS CONDIÇÕES DE ACESSIBILIDADE ESPACIAL EM SHOPPING CENTER: O CASO DO SHOPPING PELOTAS
}

\author{
ZANCHIN, Mayara (1); \\ RODEGHIERO NETO, Italo (2); \\ BROMBILLA, Douglas de Castro (3); \\ ANDRADE; Isabela Fernandes (4) \\ (1) Universidade Federal de Pelotas, Graduanda em Engenharia Ambiental e Sanitária \\ e-mail: maayfrizzo@gmail.com \\ (2) Universidade Federal de Pelotas, Graduando em Engenharia de Produção \\ e-mail: rodeghiero.hoe@gmail.com \\ (3) Instituto Federal do Rio Grande do Sul, Mestre em Arquitetura e Urbanismo \\ e-mail:douglas.brombilla@riogrande.ifrs.edu.br \\ (4) Universidade Federal de Pelotas, Doutoranda em Arquitetura e Urbanismo \\ e-mail:acessiara@gmail.com
}

\begin{abstract}
RESUMO
Para criar ambientes acessíveis a todos os usuários, é necessário o conhecimento das habilidades dos diferentes indivíduos e, ainda, das deficiências que podem acometê-los. Sendo o Shopping Center uma edificação pública utilizada por elevado número de pessoas diariamente, o projeto traz como objetivo avaliar as condições de acessibilidade espacial do Shopping Pelotas sob o ponto de vista do técnico frente ao espaço e, ainda, de dois usuários: cego e indivíduo em cadeira de rodas. Para isto, foram aplicados dois métodos: visita exploratória e passeio acompanhado. A maior parte dos resultados obtidos na visita foi ratificada nos passeios. Entretanto, alguns problemas em relação à acessibilidade espacial ainda foram identificados. Pode-se citar, como exemplo, que, embora exista piso tátil instalado nas áreas de acesso ao Shopping, o indivíduo cego não o identificou visto que sua textura se assemelha ao piso adjacente.
\end{abstract}

Palavras chave: acessibilidade espacial; visita exploratória; passeio acompanhado.

\begin{abstract}
To develop accessible environments to all your users, it is necessary the knowledge of different individuals' abilities and the deficiencies that can afflict them. Being the Shopping Center a public building used by large numbers of people daily, this article brings as main point the evaluate of the Shopping Pelotas' spatial accessibility conditions from a technical point of view and blind individuals and in a wheelchair. For this, we applied two methods: exploratory visit and accompanied walk. Most of the results in the visit could be ratified with the accompanied walk. However, some problems were identified regarding the spatial accessibility also. One we can named, for example, that while there is tactile floor installed in the access's areas to shopping, the blind person could not identified as its texture resembles the adjacent floor.
\end{abstract}

Keywords: spacial accessibility; exploratory visit; accompanied walk. 


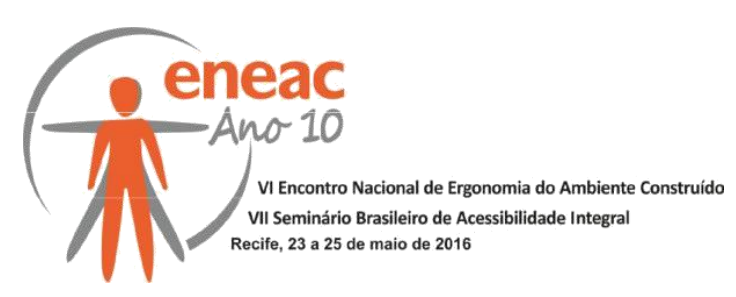

\section{INTRODUÇÃO}

A Constituição Brasileira de 1988 garante o direito de igualdade a todos os cidadãos sem que haja discriminações (DISCHINGER, 2012). Para que a inclusão aconteça, são necessárias ações que propiciem mudanças no ambiente físico para, assim, atingir melhores condições de acessibilidade espacial e permitir a todas as pessoas a realização das atividades cotidianas, de forma segura, confortável e autônoma.

Conhecer as diferentes deficiências é de essencial importância para a criação de ambientes acessíveis a todas as pessoas. Dessa forma, pode-se identificar - de forma a criar conexões - os diversos problemas que podem ocorrer no uso dos espaços e equipamentos. Segundo Guimarães (2009), só é possível atingir a acessibilidade a partir da experiência do usuário em relação ao espaço a ser construído.

Os shopping centers são espaços desenvolvidos para a utilização de todas as pessoas e, em função disso, é necessário garantir que apresentem uma configuração arquitetônica acessível. Trata-se de um espaço de uso coletivo, considerando a sua participação na realidade espacial, sociocultural e econômica nas cidades contemporâneas, e ainda de sua grande complexidade espacial e informativa (BITTENCOURT, 2013). De acordo com CARLIN (2004), o ambiente de um shopping center caracteriza-se como um espaço permanentemente monitorado e retrata, em seu interior, uma cidade idealizada, oferecendo aos seus usuários centros de consumo, lazer, alimentação e serviços em um único local e que abriga, ainda, condições de segurança. Portanto, justifica-se a escolha deste tipo de edificação para uma avaliação pós-ocupação pela diversidade de usuários atendidos diariamente.

Sendo uma edificação nova, escolheu- se o Shopping Pelotas, localizado na região sul do Rio Grande do Sul, como objeto de estudo deste trabalho. Inaugurado em 2013, as atividades do Shopping Pelotas se distribuem em um pavimento, dividido em 130 lojas, 5 âncoras, 3 megalojas, 2 restaurantes e 1.100 vagas de estacionamento (SHOPPING PELOTAS, 2014).

Isto posto, a pesquisa teve como objetivo avaliar as condições de acessibilidade espacial do Shopping Pelotas sob o ponto de vista técnico e de indivíduos cego e em cadeira de rodas. Para isso, foram adotados dois métodos: visita exploratória - com preenchimento de informações em planilhas e registro fotográfico - e passeio acompanhado com dois indivíduos: cego e em cadeira de rodas.

\section{REFERENCIAL TEÓRICO}

O artigo apresenta seu referencial teórico dividido em quatro subitens. De início, encontra-se descrito o conceito de acessibilidade espacial de forma geral, bem como seus componentes. Em seguida, apresentam- se a terminologia considerada adequada e os conceitos de deficiência e restrição. Por fim, apresentam-se as duas deficiências que serão trabalhadas ao longo da pesquisa: visual e físico-motora.

\subsection{Acessibilidade Espacial}

A Acessibilidade Espacial pode ser definida, segundo Bins Ely (2004), como a possibilidade de acesso aos mais variados lugares e atividades como também, o uso de seus equipamentos de maneira independente. Consoante Dischinger (2012), para avaliar-se edifícios públicos e privados é necessário compreender os componentes de acessibilidade espacial, divididos em quatro categorias: orientação espacial, comunicação, deslocamento e uso. 


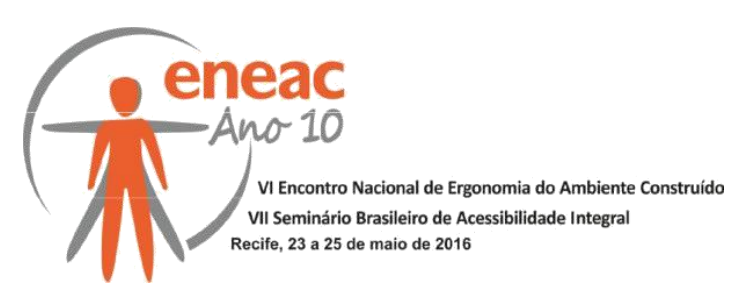

As condições de orientação espacial estão relacionadas a correta percepção do espaço por parte dos indivíduos - pela sua capacidade de receber e processar informações - e, também, pelas configurações arquitetônicas e disposição de informações adicionais no ambiente, como placas, sinais e letreiros. A componente comunicação diz respeito ás possibilidades de troca de informações interpessoais, como a utilização de tecnologia assistiva em espaços públicos. No deslocamento, faz-se necessária a possibilidade de qualquer pessoa movimentar-se ao longo de percursos horizontais e verticais de forma independente, segura e confortável. A categoria uso condiz com a possibilidade efetiva de participação e realização de atividades por todas as pessoas.

\subsection{Terminologia Adequada}

Embora a expressão "portador de deficiência", não seja a mais adequada para caracterizar uma pessoa com limitações, este é adotado no texto da constituição brasileira. Diz-se não ser o termo mais adequado pois as pessoas portam algo que seguram e podem soltar (um objeto, por exemplo). A condição de ter uma deficiência faz parte da pessoa e, tanto o verbo "portar" como o substantivo ou o adjetivo "portadora", não se aplicam a uma condição inata ou adquirida. Logo, na Convenção Internacional para Proteção e Promoção dos Direitos e Dignidade das Pessoas com Deficiência, sugeriu-se a adoção do termo "pessoas com deficiência". Pessoas com deficiência são aquelas que - por definição do Decreto no 6.949/2009 - tem impedimentos de longo prazo de natureza física, mental, intelectual ou sensorial os quais, em interação com diversas barreiras, podem obstruir sua participação plena e efetiva na sociedade. Por outro lado, o termo "deficiência" não deve ser interpretado como pejorativo ou desmerecedor.

\section{METODOLOGIA}

Inicialmente, realizou-se uma pesquisa bibliográfica acerca dos principais conceitos a serem estudados. Em seguida, foram aplicados dois métodos: visita exploratória e passeio acompanhado.

\subsection{Visita Exploratória}

A visita exploratória é caracterizada como o primeiro contato com o objeto de estudo, na qual é possível conhecer o ambiente e suas características. Segundo Ornstein e Roméro (1992), este método serve para "[... ] analisar a funcionalidade do ambiente construído, propiciando a indicação dos principais aspectos positivos e negativos do objeto de estudo".

A visita de caráter exploratório é aplicada para conhecer as características do ambiente avaliado, tendo como parâmetros comparativos normas e legislações vigentes, detectando potencialidades e desconformidades.

O instrumento escolhido para a realização desta avaliação foi desenvolvido por Dischinger, Bins Ely e Piardi (2012) e intitulado "Planilhas de Avaliação desenvolvidas pelo Programa de Acessibilidade às Pessoas com Deficiência ou Mobilidade Reduzida nas Edificações de Uso Público do Ministério Público de Santa Catarina.", conforme figura 1.

As autoras desenvolveram seis planilhas: Planilha 1- Áreas de Acesso ao Edifício; Planilha 2- Saguões, Salas de Recepção e Espera; Planilha 3- Circulações Horizontais; Planilha 4Circulações Verticais; Planilha 5- Sanitários para Deficientes; e Planilha 6- Locais para Atividades Coletivas. No caso do Shopping Pelotas, por possuir todas as atividades concentradas em um único pavimento, as planilhas de número 4 e 6 não foram aplicadas. 


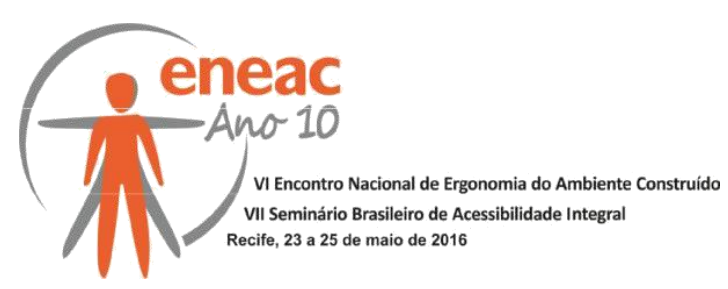

Figura 1: Planilha utilizada para a realização de método de estudo.

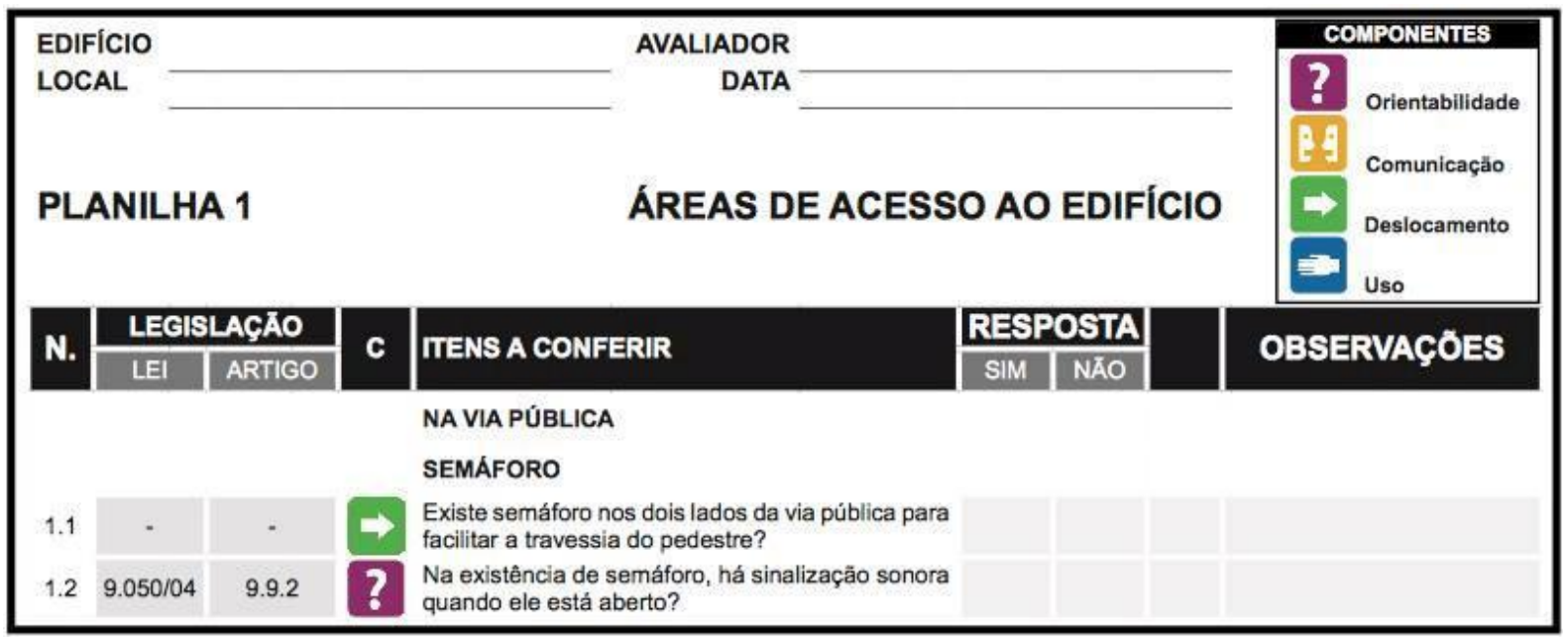

Durante a avaliação da edificação foi realizado o preenchimento das planilhas, bem como o levantamento métrico e fotográfico do espaço pelos pesquisadores.

\subsection{Passeio Acompanhado}

O método denominado passeio acompanhado, desenvolvido por Dischinger (2000), permite observar a relação existente entre o espaço e as pessoas com restrições, expondo dificuldades e facilidades encontradas para deslocar-se, comunicar-se, orientar-se e utilizar o espaço.

Esse método é realizado através de visitas acompanhadas com pessoas que possuam algum tipo de deficiência ou alguma limitação ao local de estudo. Após escolhidos os participantes, o pesquisador deve definir algumas atividades (figura 2) a serem desenvolvidas no local de interesse.

Figura 2: Atividades a serem desenvolvidas no passeio acompanhado.

\begin{tabular}{|c|l|}
\hline \multicolumn{1}{|c|}{ AMBIENTE } & \multicolumn{1}{c|}{ ATIVIDADES } \\
\hline Acesso ao Edificio & a) Encontrar o acesso ao Shopping Pelotas; \\
& b)Acessar o interior do edifício; \\
\hline Circulação no Interior do Edificio & $\begin{array}{l}\text { a) Localizar os caixas eletrônicos e guichê } \\
\text { de estacionamento; }\end{array}$ \\
b) Localizar loja C\&A (âncora); \\
ca) Localizar banheiros e telefone público; \\
\hline d) Localizar lojas Americanas (âncora);
\end{tabular}




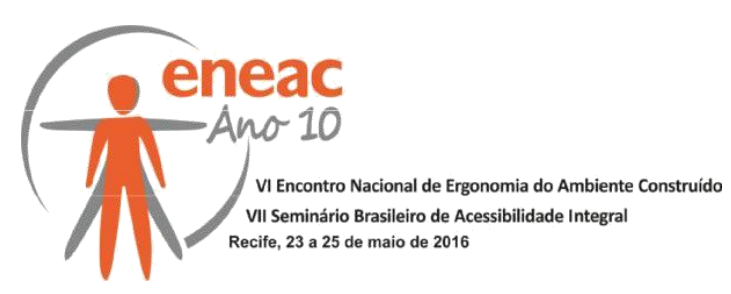

Durante o passeio, o usuário deve verbalizar suas facilidades e dificuldades ao longo do percurso. Além disso, o pesquisador registra a aplicação do método através de fotos, gravações e anotações para posterior tratamento de resultados. É importante salientar que o pesquisador não deve ajudar o usuário que está realizando o passeio, exceto em situações de risco.

\section{RESULTADOS}

A seguir, apresentam-se os resultados obtidos a partir da aplicação dos dois métodos visita exploratória e passeio acompanhado -, bem como uma discussão dos resultados atingidos.

\subsection{Visita Exploratória}

Através dos dados coletados foi possível a organização dos resultados na forma de quadros. Cada um dos quadros é composto por três colunas. Na primeira, é indicado o item conferido; a segunda evidencia o problema em si e, na última coluna, apresentam-se imagens ilustrativas dos problemas identificados. A seguir apresentam-se - como exemplo - somente duas linhas dos quadros finais, visto que os resultados são bastante extensos e, em função do tamanho limitado do artigo, não é possível expô-los na íntegra.

Quadro 1: Parte do quadro com resultados referente às áreas de acesso ao edifício.

\begin{tabular}{|c|c|c|}
\hline \multicolumn{3}{|c|}{ ESTUDO DE CASO - SHOPPING PELOTAS (Julho de 2015) } \\
\hline \multicolumn{3}{|c|}{ PLANILHA 1 - ÁREAS DE ACESSO AO EDIFÍCIO } \\
\hline ITEM CONFERIDO & OBSERVAÇÕES DO ESPAÇO & ILUSTRAÇÃO \\
\hline SEMÁFORO & $\begin{array}{l}\text { Não existe semáforo nos dois lados } \\
\text { da via pública. Porém, existe uma } \\
\text { faixa de pedestres e guias rebaixadas } \\
\text { em ambos os lados da via. Apesar de } \\
\text { rebaixadas, as guias não possuem } \\
\text { piso direcional que oriente o } \\
\text { indivíduo, da faixa, até o acesso de } \\
\text { pedestres do Shopping. }\end{array}$ & The \\
\hline PASSEIOS & $\begin{array}{l}\text { O piso na área de passeio (acesso de } \\
\text { pedestres) é antiderrapante e } \\
\text { existem dois obstáculos não } \\
\text { sinalizados. Entretanto, não existem } \\
\text { desníveis e a área livre de obstáculos } \\
\text { é superior - horizontal de } 200 \mathrm{~cm} \text { - ao } \\
\text { mínimo exigido em norma ( } 210 \mathrm{~cm} \\
\text { para vertical e } 120 \mathrm{~cm} \text { para } \\
\text { horizontal). } \\
\text { Do passeio, é possível a identificação } \\
\text { visual do edifício. Porém, não há } \\
\text { suporte informativo tátil que permita } \\
\text { a identificação por pessoas com } \\
\text { deficiência visual. }\end{array}$ & \\
\hline
\end{tabular}




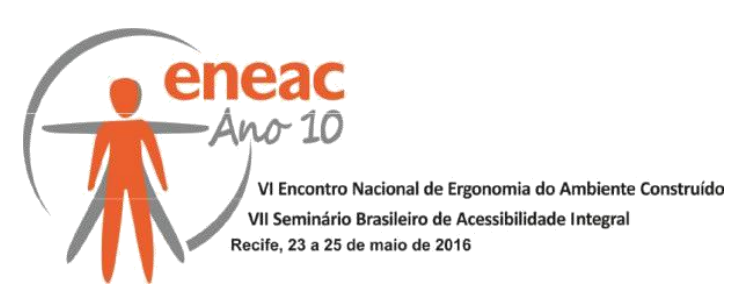

O quadro refere-se às áreas de acesso ao edifício, onde foram evidenciados problemas relacionados com os componentes orientação - como a falta de suporte informativo tátil na área de passeio nem piso direcional nas guias da via pública não (da faixa até o acesso de pedestres do Shopping). Porém, evidenciaram-se também situações positivas, como a não existência de desníveis e/ou capachos nas portas de entrada do edifício - referente ao componente deslocamento.

No segundo quadro, em relação as placas de sinalização no saguão, todas apresentam tamanho de fonte adequado, contraste entre a cor da letra e a cor do fundo e estão suspensas em altura adequada, permitindo, assim, a orientação espacial independente. Quanto aos objetos públicos disponíveis no local (telefones públicos e bebedouros), seus usos se tornam difíceis para deficientes visuais, pois não tem informação sonora ou tátil para identificá-los, e para deficientes auditivos, pois não existe tecnologias assistivas para o auxílio desta comunicação.

No terceiro quadro - referente aos sanitários -, foram identificados pequenos problemas em relação à acessibilidade. Como observado em todo o shopping, o banheiro apresenta um piso que não é antiderrapante. Observa-se, também, um aspecto discriminatório em relação aos sanitários: o Shopping apresenta três conjuntos de sanitários, sendo que apenas um possui sanitário acessível feminino para pessoas com deficiências e sanitário acessível masculino para pessoa com deficiências. Nos outros dois, apresenta-se somente um banheiro acessível, utilizado por homens e mulheres.

Por fim, através do último quadro (referente ao mobiliário), percebe-se que o mobiliário não é acessível para todas as pessoas. Não existe um assento destinado à obesos ou cadeirantes - no quesito uso - e os caixas eletrônicos e os guichês de estacionamento são acessíveis para o uso de todas as pessoas, conforme descrito na NBR de Acessibilidade 9050/2015.

\subsection{Passeio Acompanhado}

O passeio acompanhado foi realizado com um deficiente visual (cegueira total) e um participante com deficiência físico-motora (cadeirante). Ambos já conheciam o local de estudo. Com o auxilio de um gravador e de uma câmera fotográfica, foram realizados os principais registros.

\subsubsection{Deficiente Visual}

No início do passeio, João ${ }^{1}$ relatou que costuma ir sozinho ao Shopping e que os seguranças oferecem ajuda para direcioná- lo até a loja de destino. Porém, ele nunca foi aguardado para realizar sua condução até a saída do Shopping.

Logo na chegada, o participante foi conduzido à área de passeio e, partindo deste ponto, deveria encontrar a porta de acesso ao Shopping Pelotas. Identificou-se que o piso tátil tem textura muito semelhante ao material utilizado na calçada, gerando confusão ao participante na hora de realizar seu deslocamento (ilustrado na figura 3). Também foi relatado pelo participante que a falta de piso tátil indicando a mudança de direção o atrapalhou no deslocamento seguro, levando-o até um canteiro não sinalizado.

\footnotetext{
${ }^{1}$ Nome fictício para preservar o participante.
} 

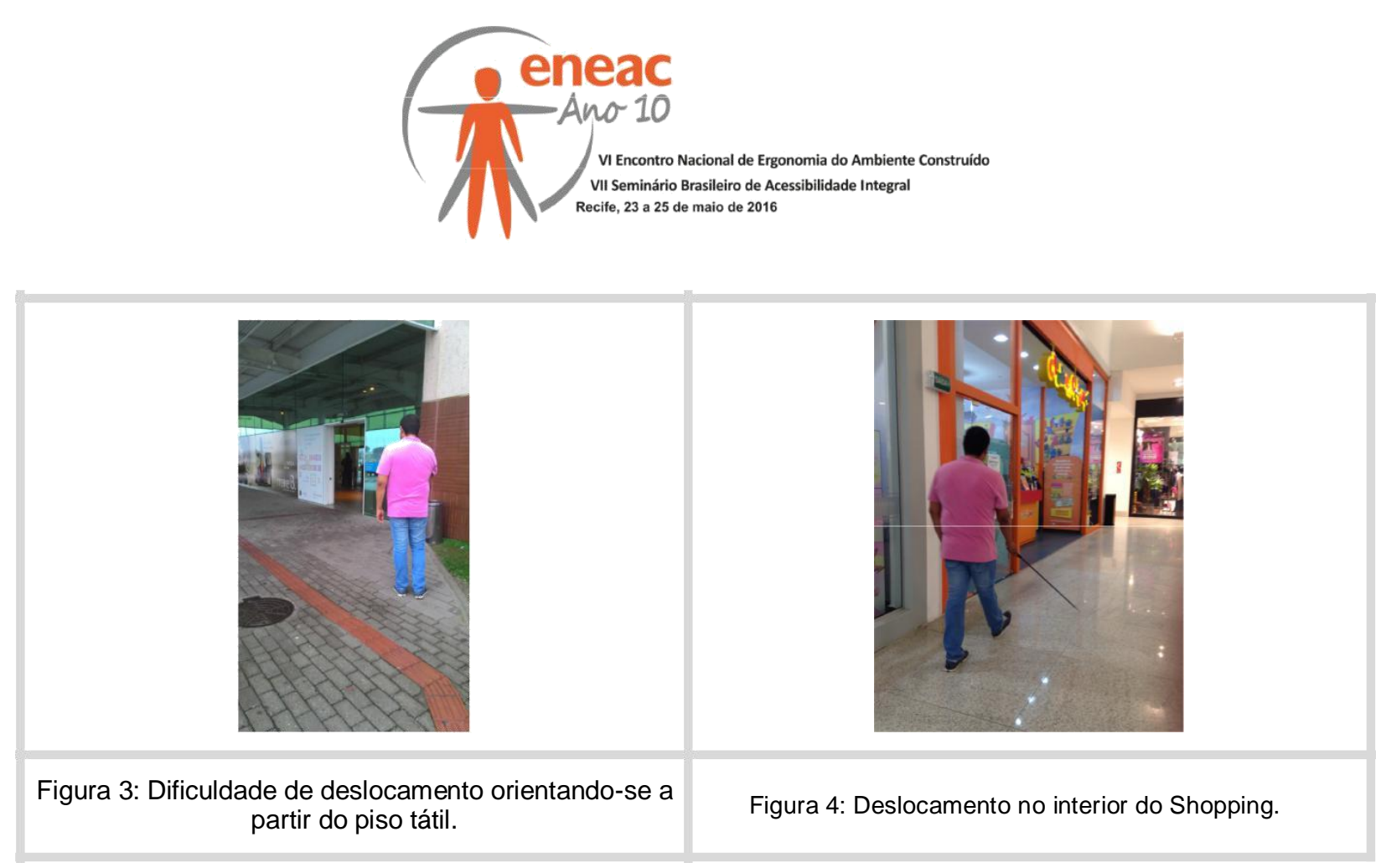

A sinalização tátil existe somente até a entrada do edifício. A partir deste ponto, não há mais nenhum piso tátil no estabelecimento. Os pesquisadores guiaram o participante para a porta interna e, também, para o interior do Shopping. O interior do estabelecimento não conta com mapa tátil.

Em seguida, para localização dos caixas eletrônicos foi margeando as lojas em direção a eles. Para isso, solicitou indicação de direção correta e utilizoua bengala e as paredes como ponto de apoio para seu deslocamento (figura 4). Ao longo do caminho, entretanto, encontrou alguns obstáculos como o vão da praça de alimentação e uma exposição de quadros impedindo sua aproximação das paredes para utilização como apoio.

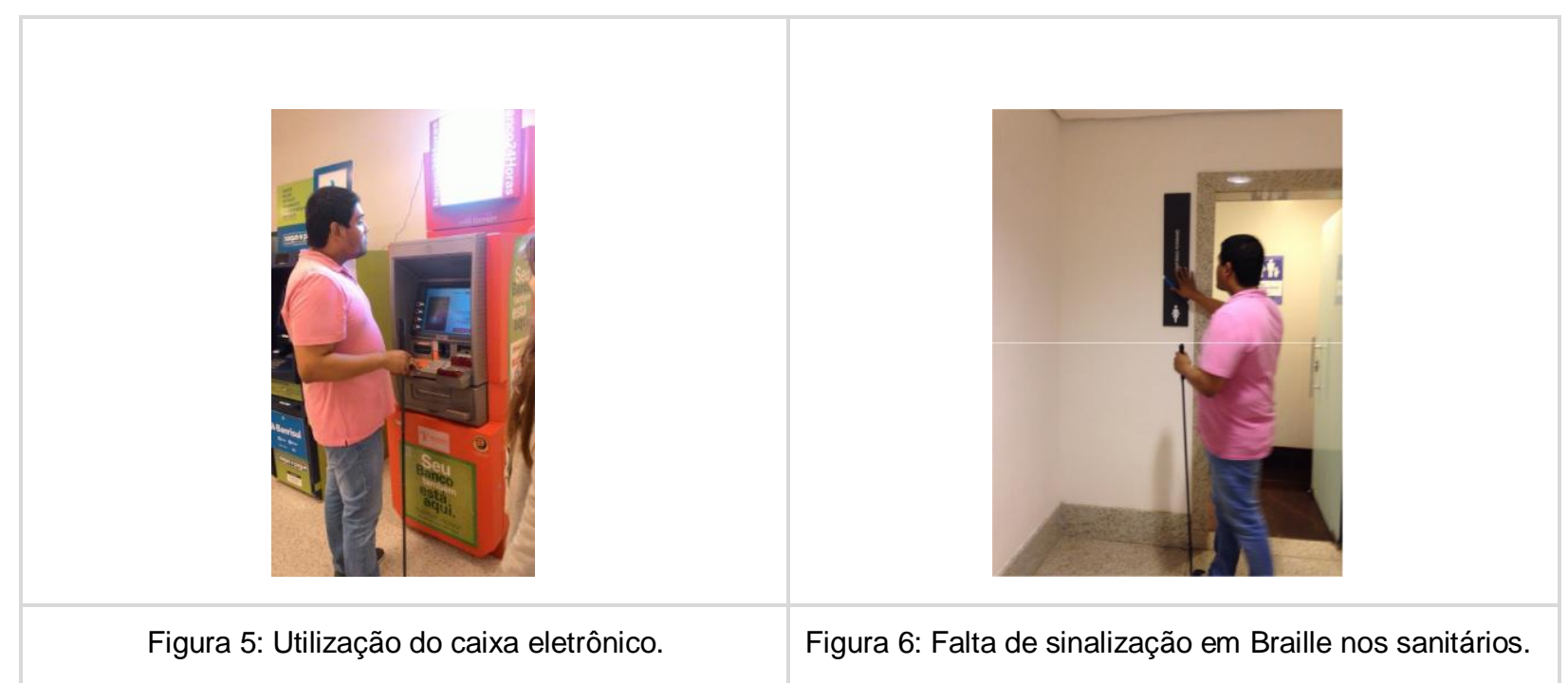

Chegando aos caixas, simulou seu uso de forma satisfatória. Todos os terminais apresentam entrada para fone de ouvido e os botões estão dispostos de forma convencional, facilitando sua identificação (figura 5). Deste ponto, foi solicitado que o participante localizasse a loja âncora "X". Não encontrou o local devido à uma área de lazer (com sofás e mesas) localizada em frente à loja "X", comprometendo sua identificação.

Para realizar a próxima etapa - localizar o banheiro masculino mais próximo -, o participante necessitou de auxílio dos pesquisadores para chegar ao local. Nos banheiros, as placas indicativas (figura 6), na lateral das portas não possuem sinalização em Braille, o que gerou confusão para o participante, que quase entrou no banheiro feminino por engano. Após ser 


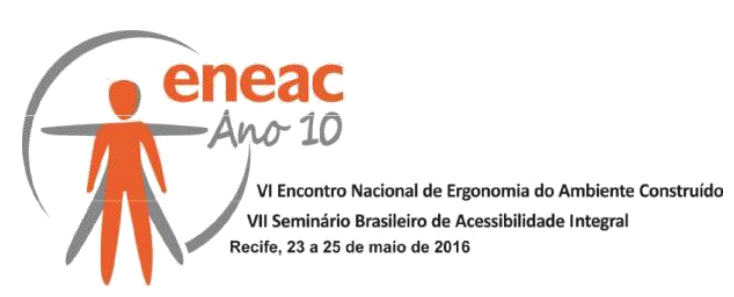

guiado para o sanitário masculino (acessível), relatou que a disposição dos móveis neste espaço está bem organizada.

Para encontrar o cinema o auxílio dos pesquisadores foi novamente necessário. Chegando à bilheteria, o participante tomou a iniciativa de perguntar aos funcionários se o espaço contava com sistema de áudio descrição para deficientes visuais e obteve, como resposta, que o cinema ainda não possui essa tecnologia.

Partindo deste ponto solicitou-se ao participante que localizasse o estabelecimento de alimentação "Y" que, só foi possível através da informação dos pesquisadores, novamente. A última atividade estabelecida no roteiro do passeio era localizar a saída, atingida pelo participante sem problemas, entretanto após indicação dos pesquisadores.

\subsubsection{Deficiente Físico-Motor}

O indivíduo em cadeira de rodas identificou o acesso ao edifício e entrou sem necessitar de auxílio, visto que as rampas possuem inclinação e dimensões adequadas, conforme observado na figura 7.

Figura 7: Entrada do edifício. $\quad$ Figura 8: Utilização do guichê de estacionamento.

A próxima atividade prevista - localizar o guichê de estacionamento e caixas eletrônicos foi atingida sem problemas por José ${ }^{2}$. Segundo seu relato, todas as medidas estavam de acordo com a norma e foi possível a utilização dos equipamentos e mobiliários disponíveis neste local. A figura 8 mostra o momento da utilização do guichê.

Logo após, o acesso as duas lojas âncoras "X" e "Z" ocorreu sem problema ou barreira durante o percurso. Em relação aos sanitários, antes mesmo de utilizá- los, o participante ressaltou que o correto seria a existência de um banheiro universal, e não um para cada tipo de deficiência, pois, desta forma, seria necessário um banheiro específico para anão e para pessoas que tenham colostomia, por exemplo. Segundo ele, o nível do vaso sanitário deveria ser um pouco mais elevado, sendo um ponto de confronto com a Norma Brasileira de Acessibilidade 9050/2015, que revela que a altura superior deve ser de, no máximo, $0,80 \mathrm{~m}$. Quanto ao uso do telefone público, não foi constatado nenhum problema, pois existe um deles que foi instalado em um nível abaixo dos demais, como observado na figura 9.

\footnotetext{
${ }^{2}$ Nome fictício adotado a fim de preservar a identidade do participante.
} 


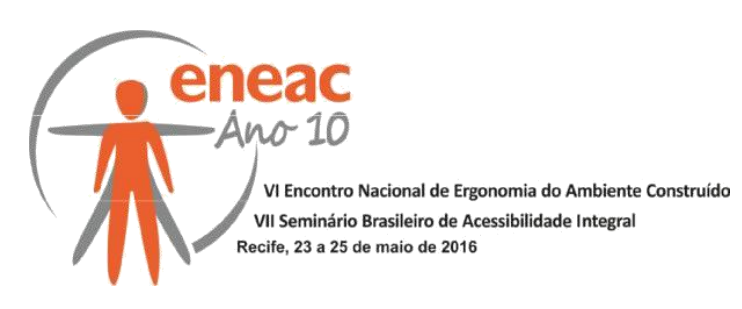

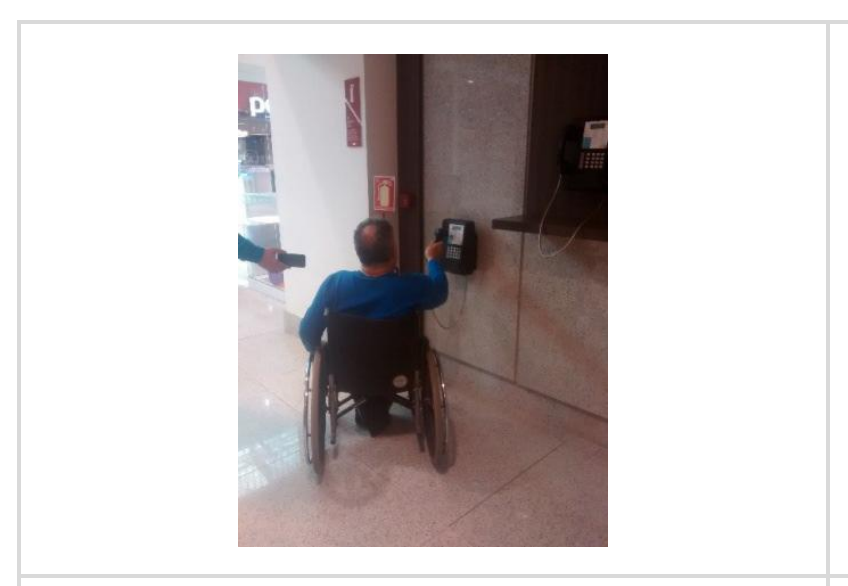

Figura 9: Utilização do telefone público.

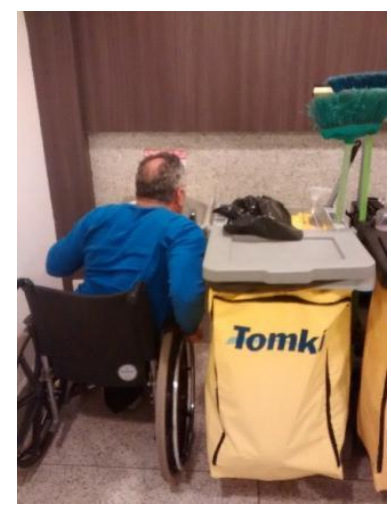

Figura 10: Impedimento de mobilidade.

O estabelecimento de cinema possui um guichê de autoatendimento que permite a compra sem utilização da fila convencional - das entradas para o filme. Este equipamento não é acessível para a utilização dos cadeirantes, visto que se encontra em altura elevada. $O$ entrevistado ressaltou que todos os caixas da bilheteria são acessíveis às pessoas em cadeira de rodas do ponto de vista da altura dos balcões e da área de aproximação.

Em seguida, foi simulada a compra de um lanche na praça de alimentação do shopping onde não foi constatado nenhum problema quando ao deslocamento neste espaço. Os testes foram feitos nos restaurantes "Y" e "W" da praça de alimentação que apresentam as áreas de acesso livres de obstáculos. A altura dos balcões, bem como a largura e outras medidas, não foram avaliadas, pois o foco da pesquisa foi a avaliação das estruturas do shopping e não o interior das lojas e estabelecimentos. O bebedouro possui a aproximação adequada para cadeirantes, porém, alguns funcionários deixaram o material de limpeza bem ao lado do equipamento, dificultando sua utilização (figura 10). Não foram identificadas dificuldades para localizar a porta e sair da edificação.

\subsection{Discussão dos resultados}

A utilização de dois métodos foi de suma importância para sanar qualquer dúvida referente aos resultados obtidos de cada um, além da complementação dos dados.

No passeio acompanhado com o deficiente visual constatou-se que, apesar de existir piso tátil na entrada do Shopping Pelotas - compreendido como adequado na visita exploratória - sua textura é muito semelhante ao piso adjacente (material utilizado na calçada), gerando confusão ao participante em seu deslocamento. No restante do trajeto, conforme evidenciado na visita técnica, não há aplicação de piso tátil no interior do edifício, impedindo a orientação do participante dentro do estabelecimento.

Identificou-se que a pessoa em cadeira de rodas pode chegar ao shopping em veículo próprio e efetuar o pagamento do ticket sem o auxílio de terceiros. Isso se justifica pois, na visita exploratória, levantou-se que a largura do estacionamento acessível estava de acordo com a norma técnica e, no passeio acompanhado, constatou-se que a altura do guichê de estacionamento está de acordo com o especificado pela norma.

O cadeirante não teve dificuldades em acessar a loja âncora "X" mesmo tendo, ao longo de seu percurso, que contornar uma área de lazer identificada pelos pesquisadores durante a visita exploratória como um obstáculo. Entretanto, o deficiente visual não localizou este espaço e enfrentou dificuldades para se deslocar neste local devido a falta de sinalização.

Foi constatado um ponto de confronto entre os métodos utilizados. A partir da planilha aplicada durante a visita exploratória, baseando-se nos parâmetros estabelecidos pela NBR 


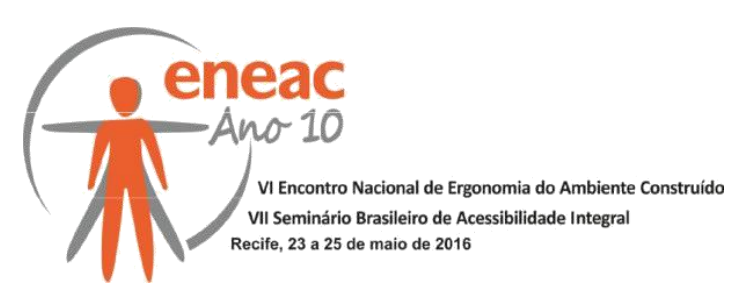

9050/2015, verificou-se que o vaso sanitário encontra-se instalado na altura sugerida. Porém, no passeio acompanhado com o cadeirante, foi relatado que o vaso poderia estar um pouco elevado em relação a altura de sua instalação a fim de facilitar a transição da cadeira para o equipamento.

\section{CONCLUSÕES}

A partir dos resultados obtidos, pode- se concluir que a utilização de dois métodos distintos um baseado nas normas e aplicado conforme o ponto de vista dos pesquisadores (visita exploratória) e outro baseado na vivência do espaço avaliado pelos usuários (passeio acompanhado) - garante a confirmação de problemas previamente identificados e, ainda, apontam outros importantes dados. Pode-se citar, por exemplo, como divergência entre os métodos, o caso do deficiente visual. Na visita exploratória, verificou-se que o piso tátil na entrada do edifício estava de acordo com a Norma Brasileira de Acessibilidade - 9050/2015. Porém, ao realizar o passeio acompanhado, o participante relatou dificuldade em orientar-se espacialmente através deste piso visto que sua textura e do piso adjacente eram semelhantes. Ainda, a ausência de um mapa tátil na entrada do edifício, para facilitar a orientação, foi relatada pelo deficiente visual como um aspecto negativo.

Além disto, como já citado anteriormente, o cadeirante relatou que o vaso sanitário poderia encontrar-se em uma altura mais elevada, facilitando a transição do indivíduo da cadeira até o objeto. Porém, na visita exploratória, observou-se que as medidas de instalação do vaso sanitário e das barras auxiliares estavam de acordo com as normas vigentes.

Embora cada indivíduo desenvolva estratégias que possibilitem participar das diferentes atividades, a partir de sua deficiência e/ou restrição, é de extrema importância que os ambientes sejam planejados e executados de forma correta e atendendo aos parâmetros mínimos estabelecidos em norma. Assim, espera-se que todos consigam, com conforto, segurança e autonomia, deslocarem-se e realizar qualquer atividade prevista nos espaços.

\section{REFERÊNCIAS BIBLIOGRÁFICAS}

ANDRADE, I.F; BINS ELY, V.M. Edificações Históricas Preservadas: Intervir para Torná-las Acessíveis. Ação Ergonômica - Revista Brasileira de Ergonomia, Florianópolis, v7, n.2, p.80, 2009.

ASSOCIAÇÃO BRASILEIRA DE NORMAS TÉCNICAS. NBR 9050: Acessibilidade a edificações, mobiliário, espaços e equipamentos urbanos. 3. ed. Rio de Janeiro: ABNT, 2015. Disponível em: http://www.pessoacomdeficiencia.gov.br/app/sites/default/files/arquivos/\%5Bfield_generico_imagensfilefield-description\%5D_164.pdf. Acesso em Novembro de 2015.

BINS ELY, V.M. Seminário Acessibilidade no Cotidiano. Palestrante da Mesa Redonda Estudos da Acessibilidade no Espaço Construído, com o tema Orientar-se no espaço: condição indispensável para a acessibilidade. 2004.

BITTENCOURT, Maria Cristina. Arquitetura de shopping centers: usabilidade relacionada à atratividade nos espaços semipúblicos para os usuários idosos / Maria Cristina Bittencourt; orientadora, Vera Lucia Duarte do Valle Pereira; co-orientador, Waldemar Pacheco Júnior. Florianópolis, SC, 2013.

CARLIN, Fernanda. Acessibilidade espacial em Shopping Centers: um estudo de caso / Fernanda Carlin ; orientadora, Vera Helena Moro Bins Ely. - Florianópolis, 2004. 191 f.: il ; tabs.

Convenção sobre os Direitos das Pessoas com Deficiência (2007). Convenção sobre os Direitos das Pessoas com Deficiência: Protocolo Facultativo à Convenção sobre os Direitos das

Pessoas com Deficiência: decreto legislativo no 186, de 09 de julho de 2008: decreto no 6.949, de 25 de agosto de 2009. -- 4. ed., rev. e atual. - Brasília : Secretaria de Direitos Humanos, Secretaria Nacional de Promoção dos Direitos da Pessoa com Deficiência, 2011.

DE ALMEIDA, Paula Aparecida Santini; BARTHOLOMEI, Carolina Lotufo Bueno. Acessibilidade de "cadeirantes" no espaço de ensino público. UNESP, Campus de Presidente Prudente - SP, 2012. 


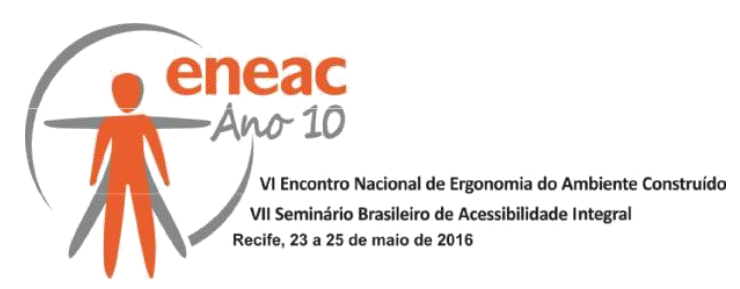

DISCHINGER, Marta. Designing for all senses: accessible spaces for visually impaired citizens. Goteborg, Suécia: Department of Space and Process, School of Architecture, Chalmers University of Technology, 2000.

DISCHINGER, Marta. Promovendo acessibilidade espacial nos edifícios públicos: Programa de Acessibilidade às Pessoas com Deficiência ou Mobilidade Reduzida nas Edificações de Uso Público / Marta Dischinger, Vera Helena Moro Bins Ely, Sonia Maria Demeda Groisman Piardi. Florianópolis: MPSC, 2012. 161 p.

GUIMARÃES, Marcelo Pinto. Uma Abordagem Holística na Prática do Design Universal. In: CORREAA, R. M. (Org.). Avanços e Desafios na Construção de uma Sociedade Inclusiva. Belo Horizonte: Editora PUC-Minas. 2009.

LIMA, P. A. Locomoção e orientação espacial como fatores de inclusão de pessoas cegas na escola e no trabalho. Revista Nossos Meios- Dez/2008.

ORNSTEIN, S.W., ROMERO, M (colaborador). Avaliação Pós-Ocupação (APO) do Ambiente Construído. São Paulo: Editora da Universidade de São Paulo, 1992.

SHOPPING PELOTAS. Informações técnicas sobre o Shopping Pelotas. Disponível em <http://www.shoppingpelotas.com.br/shopping.asp >. Acessado em: 26 de junho de 2015. 